FIG. 1.-At least 24 hours after stopping work the sweating is still profuse, and it coincides exactly with the hyperaemia.

FIG. 2.-The affected area is sharply limited and corresponds precisely to the part of the hand in contact with the vibrating surface in its grasp.

FIG. 3.-The photograph shows the hand in the position characteristic of the job (tip-stretcher). Sweating is still conspicuous on the hypothenar pad.

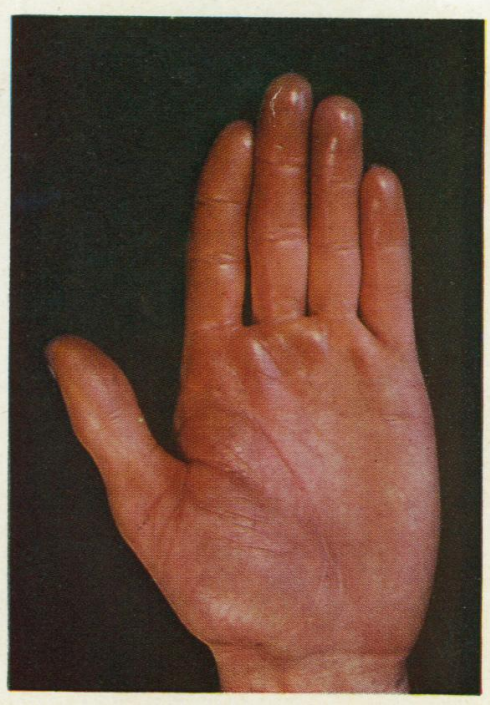

FIG. 1

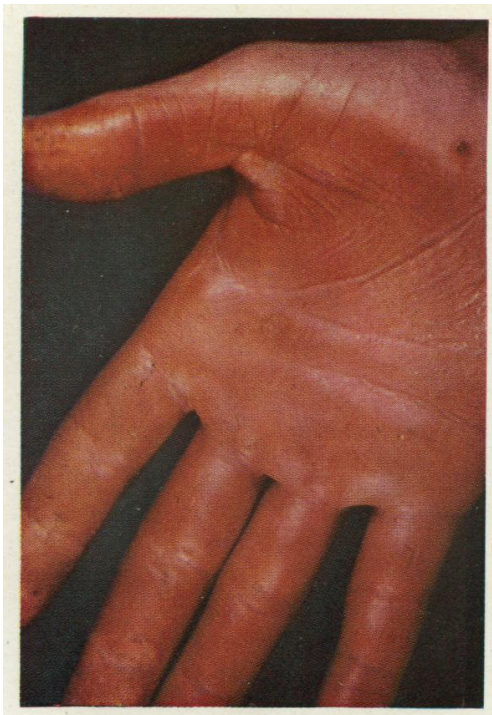

FIG. 2 


\title{
A NEW INDUSTRIAL DISEASE CALLED HYPERHIDROSIS ERYTHEMATOSA TRAUMATICA
}

\author{
BY
}

\author{
J. H. TWISTON DAVIES
}

From the Manchester and Salford Hospital for Skin Diseases

(RECEIVED FOR PUBLICATION JANUARY 23, 1951)

In the past and in the less heavily industrialized parts of the country managements were never quite as resigned as they are today to "dermatitis". Nor was any and every case of skin disease accepted by the works manager as dermatitis just because it occurred in a manual worker, however uncritically it might have been accepted on purely clinical grounds by the doctor. Thus it happened early in 1940 , at a time when all sorts of small firms were undertaking the manufacture of shell fuse caps, that the occurrence of a group of cases of " dermatitis" said to be caused by lubricating oil attracted sufficient interest for a dermatologist to be consulted.

Twelve capstan lathes had been set up in the first floor of a building which, though part of a garage, had not been used as a machine shop before. The job consisted of cutting screw threads in some steel part or other of a fuse cap, but because the steel contained an alloy to facilitate cutting, the only lubricant used was ordinary engine oil. What the works manager knew and the certifying factory surgeon did not was that the so-called "dermatitis" affected only those men who operated three particular lathes. Indeed one man who disregarded his doctor's advice never to touch oil again and carefully to avoid all dust and liquids, returned to work on one of the other machines, and had no recurrence, whereas another man who had been doing exactly the same job for six months without trouble took his place and at once developed the disease. The works manager therefore wanted me to find out for him what was the "juju" attached to these particular lathes. A loose joist under the flooring quickly supplied the answer, for the condition shown in Figs. 1, 2, and 3 is the effect of vibration and not of cutaneous sensitivity to an external irritant. Indeed it appears to have something in common with the familiar red patches on the soles of the feet of soldiers with hyperhidrosis who, in the pursuit of their calling, repeatedly stamp their feet on hard pavements. The main difference is that in the syndrome I am describing only the red areas sweat, and the signs disappear within a week. Since I have practised in the north I have seen two or three cases of this condition in " tip stretchers". These are hatters whose job it is to hold down a cone of felt for it to be beaten into the shape of a hat by an artificial head which bobs up and down with a great clatter. Fig. 3 shows not only the hyperhidrosis erythematosa traumatica but also the characteristic callosities of a " tip stretcher".

I am told on good authority that the condition has not hitherto been described, so I venture to submit this short note and to propose the sort of name for the condition that would naturally be expected of a dermatologist. 